Revista Brasil. Bot., V.32, n.2, p.361-374, abr.-jun. 2009

\title{
Anatomia do lenho de Enterolobium contortisiliquum (Vell.) Morong (Leguminosae-Mimosoideae) ocorrente em dois ambientes ${ }^{1}$
}

\author{
RIVETE S. DE LIMA ${ }^{2,5}$, PAULO L. DE OLIVEIRA ${ }^{3}$ e LIA R. RODRIGUES ${ }^{4}$
}

(recebido: 22 de junho de 2006; aceito: 18 de março de 2009)

\begin{abstract}
Wood anatomy of Enterolobium contortisiliquum (Vell.) Morong (Leguminosae-Mimosoideae) occurring in two environments). This study compares and characterizes the wood from stem of Enterolobium contortisiliquum in different environments. Samples from a total of twenty individuals were collected from plants occurring in a Caatinga area in the municipalities of Campina Grande, PB ( $7^{\circ} 11^{\prime} \mathrm{S}$ and $\left.35^{\circ} 58^{\prime} \mathrm{W}\right)$, and Buíque-PE ( $8^{\circ} 35^{\prime} \mathrm{S}$ and $37^{\circ} 14^{\prime} \mathrm{S}$ ) and in a Tropical Semidecidual Forest in the municipalities of Taquara-RS (29 $44^{\prime} \mathrm{S}$ and $50^{\circ} 50^{\prime} \mathrm{W}$ ), and Santa Maria-RS (29 $47^{\prime} \mathrm{S}$ and $\left.53^{\circ} 34^{\prime} \mathrm{W}\right)$. The areas present different climatic conditions, where Campina Grande and Buíque present the highest temperatures and lowest rainfall compared to Taquara and Santa Maria. A qualitative analysis was made through light microscopy (LM) and scanning electron microscopy (SEM). The data were submitted to descriptive statistical analysis and analysis of variance $(P \geq 0,05)$. In general, regardless of the origin the individuals examined, the wood of E. contortisiliquum presented solitary and multiple vessels, intervascular pits and alternate polygonal radiovascular alterns with shapes, vestured pits, presence of vasicentric paratraqueal parenchyma, homogeneous rays, predominantly 3 to 4 cell wide. Gelatinous fibres were observed. All individuals analyzed presented growth layers. A greater quantity of crystals and starch grains was detected in cells of the axial parenchyma of plants from the lower latitudes localities. The parametric analysis of variance confirm the associations between environment and wood anatomic characteristics of E. contortisiliquum, but show differences when data are compared to reports from other species and registered in the literature.
\end{abstract}

Key words - Caatinga, Enterolobium contortisiliquum, Tropical Semidecidual Forest, wood anatomy, wood ecological anatomy

RESUMO - (Anatomia do lenho de Enterolobium contortisiliquum (Vell.) Morong (Leguminosae-Mimosoideae) ocorrente em dois ambientes). Este estudo comparou e caracterizou a anatomia do lenho de Enterolobium contortisiliquum em ambientes distintos. As amostras foram coletadas de plantas ocorrentes na vegetação de Caatinga dos Municípios de Campina Grande, PB ( $7^{\circ} 11^{\prime} \mathrm{S}$ e $\left.35^{\circ} 58^{\prime} \mathrm{W}\right)$, Buíque-PE ( $8^{\circ} 35^{\prime} \mathrm{S}$ e $37^{\circ} 14^{\prime}$ S) e de Floresta Estacional Semidecídua nos Municípios de Taquara, RS

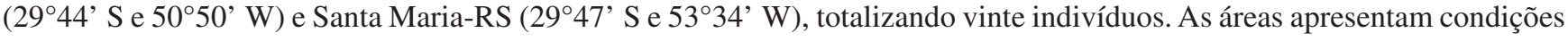
climáticas distintas, com Campina Grande e Buíque apresentando temperaturas mais elevadas e menor índice pluviométrico em comparação a Taquara e Santa Maria. Uma análise qualitativa foi realizada através da microscopia de luz (ML) e microscopia eletrônica de varredura (MEV). Os dados foram submetidos à análise estatística descritiva e à análise de variância $(P \geq 0,05)$, De um modo geral, independente da procedência dos indivíduos examinados, o lenho de E. contortisiliquum apresentou vasos solitários e múltiplos; porosidade difusa; placa de perfuração simples; pontoações intervasculares e radiovasculares alternas, com formas poligonais; pontoações guarnecidas; presença de parênquima paratraqueal vasicêntrico; raios homogêneos, predominantemente com 3 a 4 células de largura. Foram observadas fibras gelatinosas. Todos os indivíduos analisados apresentaram camadas de crescimento. Uma maior quantidade de cristais e amido foi registrada em células do parênquima axial de plantas de menores latitudes. A análise de variância paramétrica confirmou associações entre ambiente e características anatômicas do lenho de E. contortisiliquum, mas com importantes diferenças quanto ao que foi registrado na literatura para outras espécies.

Palavras-chave - anatomia da madeira, anatomia ecológica do lenho, Caatinga, Enterolobium contortisiliquum, Floresta Estacional Semidecídua

1. Parte da tese do primeiro autor, Programa de Pós-Graduação em Botânica da Universidade Federal do Rio Grande do Sul.

2. Universidade Federal da Paraíba, Departamento de Sistemática e Ecologia, Centro de Ciências Exatas e da Natureza, Campus I Cidade Universitária, 58059-900 João Pessoa, PB, Brasil.

3. Universidade Federal do Rio Grande do Sul, Departamento de Botânica. Instituto de Biociências, Av. Bento Gonçalves, 9500, Setor 4, Prédio 43423, Sala 201, 91501-970 Porto Alegre, RS, Brasil.

4. Fundação Estadual de Pesquisa Agropecuária do Rio Grande do Sul, Rua Gonçalves Dias, 570, Sala 332, 90130-060 Porto Alegre, RS, Brasil.

5. Autor para correspondência: rivete@ terra.com.br

\section{Introdução}

Os estudos em anatomia do lenho têm adquirido importância, nos últimos anos, a julgar pelo crescente número de publicações. No Brasil, esses estudos têm sido realizados principalmente com espécies arbóreas, muitas delas pertencentes à família Leguminosae, tratando de aspectos ecológicos, taxonômicos e econômicos, com o gênero Ormosia (Loureiro \& Lisboa 1979), com Copaifera langsdorffii Desf. (Marcati et al. 2001) e 
com representantes do gênero Swartzia (AngyalossyAlfonso \& Miller 2002).

Com cerca de 19.325 espécies, distribuídas em aproximadamente 727 gêneros, a família Leguminosae (Fabaceae) está atualmente constituída por três subfamílias: Caesalpinioideae, Papilionoideae e Mimosoideae (Lewis at al. 2005). O gênero Enterolobium Mart. pertence à tribo Ingea, considerada a mais derivada dentro da subfamília Mimosoideae e apresenta 11 espécies com distribuição exclusivamente neotropical, sendo o Brasil o seu provável centro de dispersão (Lewis at al. 2005).

Nativa nas formações florestais, especialmente do domínio de Mata Atlântica, E. contortisiliquum é encontrada, também, em formações de cerrado do Brasil Central. Na região Nordeste, ocorre na zona do Agreste e na caatinga (Mesquita 1990). Na região Sul, ocorre em florestas estacionais, campos e restingas arbustivas. Encontra-se, também, na Argentina, Bolívia, Paraguai e Nordeste do Uruguai (Muñiz 1993).

Trata-se de uma espécie heliófila, pouco exigente quanto às características do solo, e de crescimento rápido, sendo empregada, por isso, em florestamentos e reflorestamentos, atendendo a inúmeros objetivos que envolvem do paisagismo à recuperação de áreas degradadas. A madeira de E. contortisiliquum é leve e, por isso, pode ser aproveitada na fabricação de brinquedos, peças de artesanato, canoas, telhados, embalagens e caixotes (Mainieri \& Chimelo 1989).
Apesar da importância ecológica e do potencial para emprego econômico, os estudos voltados para essa espécie ainda estão em uma etapa inicial. Dessa forma, para ampliar os conhecimentos em anatomia de $E$. contortisiliquum, foi executado um trabalho com o objetivo de caracterizar, qualitativamente e quantitativamente, a variabilidade morfológica dos constituintes do seu lenho e correlacioná-la com possíveis adaptações da espécie aos diferentes ambientes.

\section{Material e métodos}

Foram examinadas amostras do lenho de indivíduos ocorrentes nos Municípios de Campina Grande-PB ( $7^{\circ} 11^{\prime} \mathrm{S}$ e $\left.35^{\circ} 58^{\prime} \mathrm{W}\right)$, Buíque-PE ( $8^{\circ} 35^{\prime} \mathrm{S}$ e $\left.37^{\circ} 14^{\prime} \mathrm{S}\right)$, TaquaraRS $\left(29^{\circ} 44^{\prime} \mathrm{S}\right.$ e $\left.50^{\circ} 50^{\prime} \mathrm{W}\right)$ e Santa Maria-RS (29 $47^{\prime} \mathrm{S}$ e $\left.53^{\circ} 34^{\prime} \mathrm{W}\right)$.

Nos Municípios de Campina Grande e Buíque, os indivíduos foram coletados dentro da vegetação de Caatinga, formada por arbustos e árvores de pequeno porte, com características xeromorfas. Já nos Municípios de Taquara e Santa Maria, as coletas foram na Floresta Estacional Semidecídua, com árvores de maior porte em comparação com a Caatinga. Nos dois ambientes, o fenômeno da caducifolia é comum em grande número de seus representantes.

O critério de escolha das áreas de coleta foram as distintas condições climáticas, vegetacionais e latitudinais das duas regiões (tabela 1 ).

Tabela 1. Caracterização das quatro áreas de estudos de Enterolobium contortisiliquum.

Table 1. Characterization of the four study sites of Enterolobium contortisiliquum.

\begin{tabular}{lcccc}
\hline & Buíque & Campina Grande & Taquara & Santa Maria \\
\hline Dados gerais & & & & \\
Região geográfica & Nordeste & Nordeste & Sul & Sul \\
Estado da Federação & Pernambuco & Paraíba & Rio G. do Sul & Rio G. do Sul \\
Latitude & $8^{\circ} 35^{\prime} \mathrm{S}$ & $7^{\circ} 11^{\prime} \mathrm{S}$ & $29^{\circ} 44^{\prime} \mathrm{S}$ & $29^{\circ} 47^{\prime} \mathrm{S}$ \\
Longitude & $37^{\circ} 14^{\prime} \mathrm{W}$ & $35^{\circ} 58^{\prime} \mathrm{W}$ & $50^{\circ} 50^{\prime} \mathrm{W}$ & $53^{\circ} 34^{\prime} \mathrm{W}$ \\
Altitude $(\mathrm{m})$ & 780 & 665 & 68 & 173 \\
Vegetação & Caatinga & Caatinga & Floresta & Floresta \\
Dados climatológicos & & & & $1961-1990$ \\
Período das medições & $1973-1990$ & $1961-1990$ & $1923-1949$ & 18,8 \\
Temperatura média anual $\left({ }^{\circ} \mathrm{C}\right)$ & 22,9 & 23,3 & 19,5 & 24,9 \\
Média das máximas $\left({ }^{\circ} \mathrm{C}\right)$ & 29,3 & 27,5 & 24,8 & 14,2 \\
Média das mínimas $\left({ }^{\circ} \mathrm{C}\right)$ & 18,5 & 19,2 & 15,6 & $2.174,5$ \\
Insolação total anual $(\mathrm{h})$ & $2.768,4$ & $2.224,0$ & $2.244,6$ & 77,0 \\
Evaporação total potencial $(\mathrm{mm})$ & $1.828,3$ & $1.417,4$ & 983,0 & 76,0 \\
Umidade relativa média anual $(\%)$ & 69,6 & 82,7 & $1.347,4$ & $1.686,1$ \\
Precipitação média anual $(\mathrm{mm})$ & 694,2 & 802,7 & & \\
\hline
\end{tabular}

(Fontes/Sources: Machado 1950, DNMET 1992) 
Foram coletadas amostras do lenho de 20 indivíduos, cinco em cada local de coleta, todos com diâmetro à altura do peito entre 39 e $80 \mathrm{~cm}$ (DAP, medido a 1,30 m do solo). Utilizou-se um método não-destrutivo para coleta das amostras. Para tal, foram feitas incisões de $4 \mathrm{~cm}$ de profundidade (desconsiderando a espessura da casca), $10 \mathrm{~cm}$ de largura e $6 \mathrm{~cm}$ de altura, no caule de cada indivíduo, com o auxílio de serrote e formão. A amostra foi removida e a lesão foi coberta com solução aquosa saturada de sulfato de cobre, buscando prevenir o ataque de organismos xilófagos e/ou fitopatogênicos. Do material botânico coletado, foram preparadas exsicatas e depositadas no Herbário Dárdano de Andrade-Lima (IPA)

As amostras do lenho encontram-se depositadas no Laboratório de Anatomia Vegetal do Departamento de Sistemática e Ecologia da Universidade Federal da Paraíba (UFPB). Informações sobre os números das lâminas depositadas no Laboratório de Anatomia Vegetal da UFPB, DAP, número de Herbário e altura das plantas encontram-se na tabela 2.

As preparações histológicas seguiram as técnicas usuais em anatomia vegetal apresentadas por Johansen (1940). Para tal, da região mais externa de cada amostra de lenho foram retirados corpos de prova, com cerca de $1,5 \mathrm{~cm}^{3}$. As amostras foram amolecidas por cozimento e seccionadas, com aproximadamente $15 \mu \mathrm{m}$ de espessura, em micrótomo de deslize Reichert. As secções foram, posteriormente, clarificadas em hipoclorito de sódio 3\%, lavadas em água destilada e submetidas à coloração com safranina $1 \%$ em etanol $50 \%$. As secções foram desidratadas em série etanólica até acetato de butila e montadas entre lâmina e lamínula com Entelan ${ }^{\circledR}$.

Para o estudo dos elementos celulares dissociados utilizou-se material proveniente dos $4 \mathrm{~mm}$ mais externos do lenho em contato com a região cambial. Fragmentos do material foram macerados em uma mistura de peróxido de hidrogênio $3 \%$ e ácido acético glacial $98 \%$ na proporção de $1: 1(\mathrm{v} / \mathrm{v})$, corados em safranina aquosa $1 \%$ e montados em glicerina em lâminas semipermanentes. (modificado de Franklin 1945 apud Kraus \& Arduin, 1997).

Algumas secções, que não passaram pelos processos acima, foram tratadas com lugol para detecção de amido e ácido clorídrico a $10 \%$ para teste da insolubilidade dos cristais (Johansen 1940).

Os registros fotomicrográficos foram feitos a partir das lâminas permanentes e semipermanentes, utilizando os fotomicroscópios Leica - modelo DMR e Olympus-modelo BX 41 dos Laboratórios de Anatomia Vegetal da Universidade Federal do Rio Grande do Sul e da Universidade Federal da Paraíba.

Para as análises em MEV, secções longitudinais tangencias do lenho, com espessura variando ente $100 \mathrm{e}$ $200 \mu \mathrm{m}$, foram desidratadas em série alcoólica, secas em estufa $\left(60^{\circ} \mathrm{C} \sim 12 \mathrm{~h}\right)$, coladas no porta-objeto (stub) com etiqueta dupla-face de carbono e metalizadas com ouro. Observações e eletromicrografias foram feitas com o auxílio dos Microscópios Eletrônicos de Varredura modelos JEOL - JSM 5800 e JSM 6060 em 20 kV do Centro de Microscopia Eletrônica (CME) da Universidade Federal do Rio Grande do Sul.
Tabela 2. Material analisado de Enterolobium contortisiliquum. $(\mathrm{Nr}=$ número da lâmina depositada no Laboratório de Anatomia Vegetal da Universidade Federal da Paraíba-UFPB; DAP = Diâmetro do caule à altura do peito).

Table 2. Analyzed specimens of Enterolobium contortisiliquum. $(\mathrm{Nr}=$ slide number deposited at the Laboratory of Plant Anatomy (Universidade Federal da Paraíba-UFPB); DAP = Stem diameter at breast height).

\begin{tabular}{lcccc}
\hline Local de coleta & $\begin{array}{c}\text { № Herbário } \\
\text { (IPA) }\end{array}$ & $\begin{array}{c}\mathrm{Nr} \\
(\mathrm{cm})\end{array}$ & $\begin{array}{c}\text { DAP } \\
(\mathrm{m})\end{array}$ & Altura \\
\hline Buíque - PE & & & & \\
Indivíduo 1 & 82.585 & 132 & 54,4 & 15 \\
Indivíduo 2 & 82.586 & 133 & 38,8 & 14 \\
Indivíduo 3 & 82.587 & 134 & 52,2 & 15 \\
Indivíduo 4 & 82.588 & 135 & 64,9 & 17 \\
Indivíduo 5 & 82.589 & 136 & 62,7 & 12 \\
Campina Grande - PB & & & & \\
Indivíduo 1 & 82.590 & 142 & 62,3 & 13 \\
Indivíduo 2 & 82.591 & 145 & 43,2 & 12 \\
Indivíduo 3 & 82.592 & 146 & 42,3 & 17 \\
Indivíduo 4 & 82.593 & 147 & 73,8 & 18 \\
Indivíduo 5 & 82.594 & 148 & 63,6 & 15 \\
Taquara - RS & & & & \\
Indivíduo 1 & 82.595 & 152 & 51,5 & 16 \\
Indivíduo 2 & 82.596 & 153 & 80,0 & 15 \\
Indivíduo 3 & 82.597 & 153 & 55,3 & 14 \\
Indivíduo 4 & 82.598 & 155 & 52,2 & 20 \\
Indivíduo 5 & 82.599 & 156 & 39,7 & 15 \\
Santa Maria - RS & & & & \\
Indivíduo 1 & 82.600 & 163 & 46,4 & 12 \\
Indivíduo 2 & 82.601 & 164 & 38,8 & 12 \\
Indivíduo 3 & 82.602 & 165 & 47,7 & 13 \\
Indivíduo 4 & 82.603 & 166 & 50,6 & 12 \\
Indivíduo 5 & 82.604 & 167 & 51,5 & 12 \\
\hline
\end{tabular}

As contagens e medições foram realizadas com o auxílio de uma câmara clara acoplada ao microscópio e de uma objetiva com escala micrométrica. Para cada característica do lenho, foram realizadas 90 medições por indivíduo amostrado, totalizando 1.800 medições de cada parâmetro celular. Foram feitas medições dos seguintes parâmetros anatômicos (variáveis): diâmetro tangencial dos vasos (DTV) em $\mu \mathrm{m}$, comprimento dos elementos de vaso (CV) em $\mu \mathrm{m}$, freqüência dos vasos (FV) em número de células por $\mathrm{mm}^{2}$, comprimento das fibras (CF) em $\mu \mathrm{m}$, altura dos raios ( $\mathrm{ARn}$ - em número de células e $\mathrm{AR}$ - em $\mu \mathrm{m}$ ) e largura dos raios $(\mathrm{LRn}-\mathrm{em}$ número de células e $\mathrm{LR}-\mathrm{em} \mu \mathrm{m})$. A freqüência dos vasos representa o número de vasos por $\mathrm{mm}^{2}$, 
ou seja, a densidade de vasos. Apesar de ser inadequado, o termo freqüência foi utilizado por recomendação do IAWA Committee (1964, 1989). Os valores absolutos de cada variável foram submetidos à análise estatística descritiva para obtenção de medidas de tendência central (média e mediana) e medidas de dispersão (desvio padrão, coeficiente de variação e amplitude). Em seguida, os valores absolutos foram submetidos aos testes de normalidade e de igualdade das variâncias. Os dados foram ajustados e/ou transformados, visando a distribuição normal e a eliminação de pseudoreplicação, para a viabilização da análise de variância (ANOVA) paramétrica. Para as variáveis de distribuição contínua: $\mathrm{CF}$, CV, DTV e AR, a ANOVA utilizou dados de duas lâminas, cada uma com 30 observações (totalizando 1.200 observações). Para as variáveis de distribuição descontínua: FV, ARn, LRn e LR, a ANOVA foi feita sobre as médias de cada uma das três lâminas. Nesse caso, o no de repetições foi de três por indivíduo, totalizando 60 observações. Os valores ajustados e/ou transformados foram submetidos à ANOVA paramétrica e as médias foram comparadas pelo teste de Tukey com $5 \%$ de probabilidade de erro.

Os testes estatísticos foram executados através dos softwares: Excel - Microsoft Corporation (2002), SigmaStat para Windows, versão 2.03 - SPSS Inc. (1992-1997) e SAS para Windows - SAS Institute Inc. (1999).

\section{Resultados e discussão}

O lenho de E. contortisiliquum apresenta camadas de crescimento demarcadas pelo achatamento radial ou redução do lume das fibras (figura 1). Essas camadas foram observadas em todas as amostras analisadas, independente do local de coleta. Por outro lado, as camadas de crescimento foram anteriormente descritas como indistintas em E. contortisiliquum (Mainieri \& Chimelo 1989) e formadas por zonas fibrosas em E. maximum Ducke (Fedalto et al. 1989). A existência de camadas de crescimento no lenho de espécies de regiões temperadas e tropicais é conhecida há muito tempo, sendo mais comum em plantas de zonas temperadas como ressaltado por Wheeler et al. (2007). Por sua grande importância ecofisiológica, a atividade sazonal dessas espécies tem recebido a atenção dos vários pesquisadores que investigam a anatomia do lenho no estudo da anatomia ecológica, da periodicidade de crescimento e da atividade cambial, como Iqbal \& Ghouse (1987) e Luchi (2004) dentre outros. Ocorrência de camadas de crescimento em plantas de ambientes com disponibilidade hídrica irregular, a exemplo do cerrado e caatinga, é bem marcante. Marcati et al. (2006) ao analisarem o lenho de 48 espécies de cerrado verificaram que $33 \%$ das espécies apresentaram camadas de crescimento mal definidas e que $61 \%$ possuíam camadas bem definidas. Camadas de crescimento, também, foram observadas em Lippia salviifolia ocorrente no cerrado e correlacionadas às variações pluviométricas (Goulart \& Marcati 2008). Assim, a presença de camadas de crescimento nos indivíduos de E. contortisiliquum demonstra uma clara resposta da planta às condições adversas do ambiente, em especial, à baixa disponibilidade de água, como ocorre na Floresta Estacional Semidecídua e na Caatinga, durante certo período do ano.

O lenho de E. contortisiliquum exibiu vasos predominantemente solitários (65\%) (figura 2). Quando múltiplos (35\%), os vasos formaram grupos de 2 a 7. Porosidade difusa e freqüência média de 2 vasos por $\mathrm{mm}^{2}$. A maior percentagem de vasos solitários em $E$. contortisiliquum também foi registrada por Mainieri \& Chimelo (1989) e Muñiz (1993). Além disso, a presença de vasos múltiplos e solitários com porosidade difusa é muito freqüente em espécies lenhosas da flora brasileira ocorrentes em diversos ecossistemas como foi observado no estudo feito por Alves \& Angyalossy-Alfonso (2000). O diâmetro tangencial dos vasos das plantas estudadas variou de $17 \mu \mathrm{m}$ a $349 \mu \mathrm{m}$, com média de $197 \mu \mathrm{m}$, não se distanciando dos valores observados por Metcalfe \& Chalk (1950) para o gênero Enterolobium. Essa média está próxima, também, das encontradas por Mainieri \& Chimelo (1989) e Muñiz (1993) para a mesma espécie, de $188 \mu \mathrm{m}$ e $200 \mu \mathrm{m}$, respectivamente. Fedalto et al. (1989) constataram um diâmetro tangencial médio de $239 \mu \mathrm{m}$ para outra espécie do gênero, E. maximum. Os elementos de vaso são curtos, com comprimento médio de $342 \mu \mathrm{m}$ e placas de perfuração simples (figura 3). As pontoações intervasculares são alternas, com formas poligonais a arredondadas; aberturas linear elípticas, inclusas horizontais, de tamanho médio, com diâmetro tangencial médio de $7 \mu \mathrm{m}$ e guarnecidas (figuras 4-6). As pontoações radiovasculares são semelhantes às intervasculares.

A presença de pontoações guarnecidas é uma característica marcante em vários grupos da família Leguminosae (Metcalfe \& Chalk 1950, Carlquist 2001, Jansen et al. 2001) e foi registrada em E. contortisiliquum (Mainieri \& Chimelo 1989, Muñiz 1993) e em E. maximum (Feldato et al. 1989). Além disso, outros representantes da flora brasileira, pertencentes à família Leguminosae, apresentam o mesmo tipo de pontoação, destacando-se Copaifera langsdorffii ocorrente em floresta e cerradão (Marcati et al. 2001), em espécies do gênero Swartzia (Angyalossy-Alfonso \& Miller 2002) e nos indivíduos de Pseudopiptadenia contorta (DC.) G. P. Lewis \& M. P. Lima (Ribeiro \& Barros 2006) ocorrentes em dois remanescentes de Floresta Atlântica. 

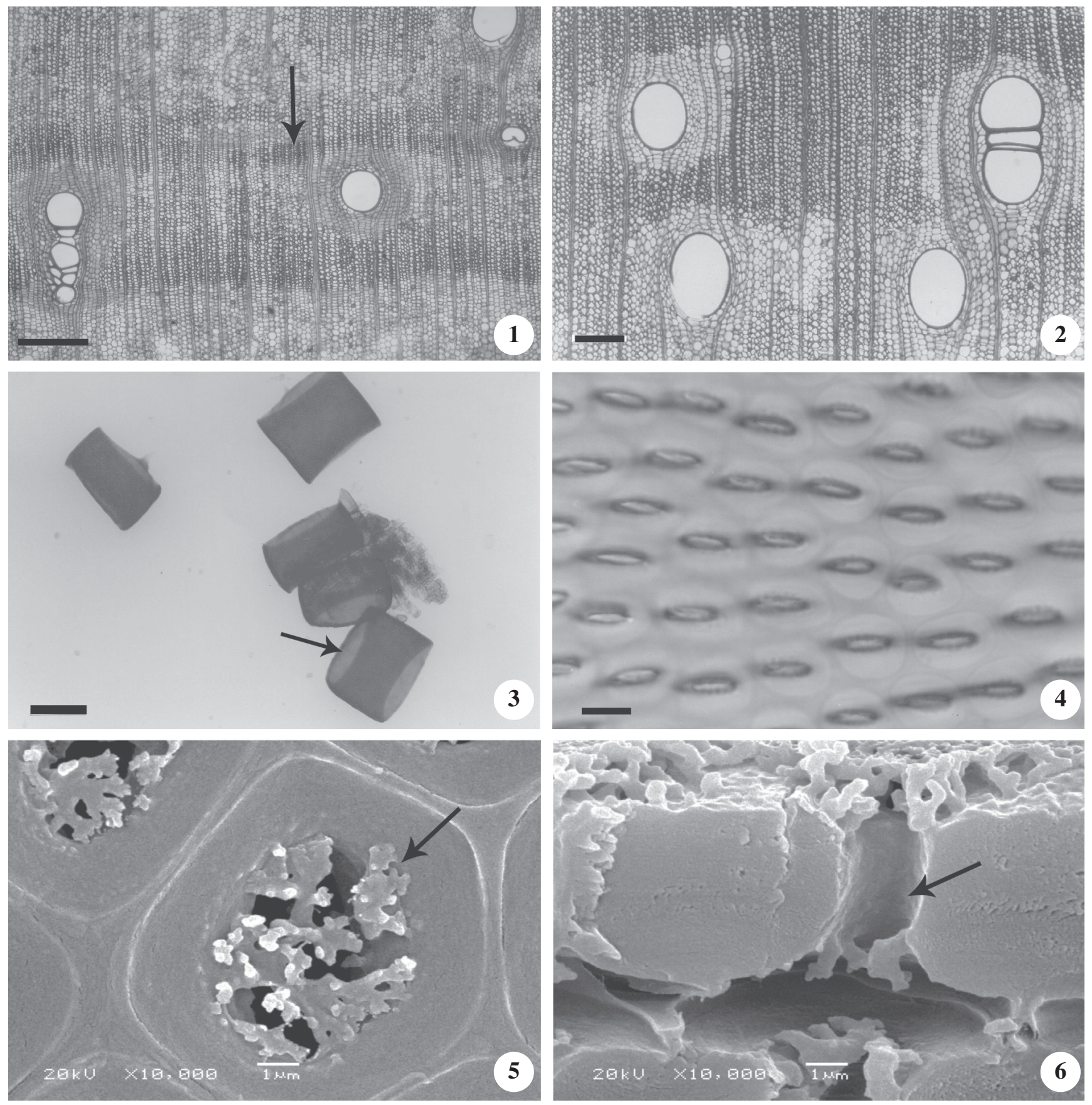

Figuras 1-6. Lenho do caule de Enterolobium contortisiliquum. 1-4. Fotomicrografia. 5, 6. Eletromicrografia de varredura. 1-2. Secções transversais do lenho. 1. Camadas de crescimento delimitadas por achatamento radial das fibras (seta). 2. Vasos solitários e múltiplos, parênquima vasicêntrico, aliforme a confluente. 3. Lenho macerado mostrando elementos de vaso com placa de perfuração simples (seta). 4. Pontoações intervasculares alternas do elemento de vaso. 5, 6. Pontoações guarnecidas no elemento de vaso. 5. Detalhe da pontoação guarnecida, mostrando guarnições na abertura da pontoação (seta). 6. Canal da pontoação (seta). Barra $=500 \mu \mathrm{m}(1) ; 250 \mu \mathrm{m}(2,3) ; 5 \mu \mathrm{m}(4)$.

Figures 1-6. Wood of stem of Enterolobium contortisiliquum. 1-4. Ligth micrographs. 5, 6. Scanning electron micrographs. Transverse sections of the wood. 1. Growth rings demarcated by radially flattened fibers (arrow). 2. Solitary and multiple vessels, vasicentric parenchyma, aliform confluent. 3. Macerated wood showing vessel elements with simple perforation plates (arrow). 4. Alternate intervessel pits of vessel element. 5, 6. Vestured pits in vessel element. 5. Detail of vestured pits, showing vestures around bordered pit. 6 . Pit canal. Bar $=500 \mu \mathrm{m}(1) ; 250 \mu \mathrm{m}(2,3) ; 5 \mu \mathrm{m}(4)$. 
Bailey (1933) foi um dos primeiros a estudar e caracterizar morfologicamente as pontoações guarnecidas. Em seus estudos ele classificou esse tipo de estrutura em quatro tipos distintos, sendo posteriormente ampliado para 15 tipos por Ohtani \& Ishida (1976). O valor taxonômico das pontoações guarnecidas foi referido por Bailey (1933) após analisar 152 famílias botânicas e verificar a presença de pontoações guarnecidas nos elementos de vaso de 25 delas. Essa importância taxonômica, também, foi citada por Carlquist (2001). Segundo Jansen et al. (2001, 2004) as pontoações guarnecidas mostram-se como um caráter conservativo dentro de vários grupos monofiléticos e podem caracterizar as ordens Myrtales e Gentianales, assim como as famílias Polygonaceae, Brassicaceae e Malpighiaceae. Entretanto, o emprego das pontoações na taxonomia deve ser cauteloso, devido à sua variação morfológica e a ocorrência de diferentes tipos dentro do mesmo indivíduo, conforme registrado por Jansen et al. (1998). Além da variação morfológica, pode ocorrer diferença na composição química das pontoações guarnecidas, como observado por Watanabe et al. (2006), e até mesmo com relação a presença ou ausência das pontoações dependendo dos efeitos da poluição, como verificado em Tibouchina pulchra Cogn. (Mazzoni-Viveiros 2000). O importante papel das pontoações guarnecidas no fluxo de água no corpo da planta, regulando a pressão osmótica, auxiliando na difusão da água, gases e outras substâncias e evitando o risco de embolias, foi registrado por Zweypfenning (1978) e Carlquist (2001). Utilizando dados da literatura, Jansen et al. (2004) registraram, em um universo de 11.843 , um percentual de $32 \%$ de espécies com pontoações guarnecidas. Já Wheeler et al. (2007), analisando as descrições 5.663 espécies registradas no InsideWood database, verificaram que $28 \%$ das espécies apresentavam pontoações guarnecidas, indicando a necessidade de se buscar melhor conhecer tais estruturas.

Assim, estudos mais aprofundados acerca da presença de pontoações guarnecidas em representantes da família Leguminosae, a exemplo de E. contortisiliquum, poderão contribuir para os estudos da taxonomia e ecofisiologia do grupo.

Observou-se, em todos os indivíduos de $E$. contortisiliquum, parênquima axial do tipo paratraqueal vasicêntrico, com tendência a aliforme e confluente (figura 2). Também foi detectada grande quantidade de amido em células subdivididas do parênquima axial (figura 7). O acúmulo de solutos em células do parênquima é comumente aceito como uma resposta de plantas submetidas à seca, pois favorece a absorção de água através de diminuições do potencial hídrico. A quebra de amido, liberação de açúcares no xilema e retenção de aminoácidos (como prolina) são alguns dos principais mecanismos de osmorregulação, presentes nas plantas, que contribuem para regulação do balanço hídrico e evitam que a perda excessiva de água seja capaz de causar embolia nos vasos xilemáticos (Sperry et al. 2002, Hacke \& Sperry 2003).

Braun (1984) estudando espécies decíduas ocorrentes em regiões temperadas e tropicais observou que as células do parênquima radial e axial armazenavam amido, permitindo sua rápida mobilização, visto que se encontravam próximas aos elementos condutores do xilema. Este mecanismo seria garantido através da atividade contínua da fosfatase ácida, ao liberar constantemente açúcares para os vasos e manter elevada a pressão osmótica em seu interior. Como a perda das folhas tornaria a taxa de transpiração nula, a liberação de açúcares para o interior dos vasos manteria a fluxo contínuo de água dentro dos mesmos. A importância dos açúcares, na forma de amido, presente nas células de parênquima paratraqueal também foi observada por Hacke \& Sperry (2003) ao estudarem, sob diferentes condições de potencial hídrico e pressão osmótica, o xilema de indivíduos de Laurus nobilis L. e Acer negundo L. mantidos em condições de laboratório. Os autores observaram que o deslocamento de açúcares, das células parenquimáticas para o interior dos vasos, restabelece o fluxo de água no xilema e minimiza os efeitos da embolia. Assim, a grande quantidade de amido em células do parênquima axial observada nos indivíduos de E. contortisiliquum pode estar relacionada ao caráter caducifólio da espécie, como observado por Braun (1984), e funcionar como uma estratégia para garantir o fluxo contínuo de água nos vasos, podendo ainda evitar embolias como confirmado por Hacke \& Sperry (2003).

Foram observados raios extremamente baixos, com 14 células de altura e medindo $234 \mu \mathrm{m}$, muito estreitos, com 3 células de largura e medindo $31 \mu \mathrm{m}$ (figura 8). Há predomínio de parênquimas radiais trisseriados (46\%) e bisseriados (33\%). Os raios são homogêneos e constituídos unicamente por células procumbentes (figura 9). Mainieri \& Chimelo (1989) encontraram em E. contortisiliquum raios homogêneos, com cerca de $310 \mu \mathrm{m}$ de altura e largura variando entre 1 e 4 células. Muñiz (1993) registrou, na mesma espécie, raios homogêneos, com 15 células de altura e 3 células de largura, valores muito próximos aos encontrados neste trabalho. Nos indivíduos analisados, foram observados cristais prismáticos de oxalato de cálcio em células do parênquima axial, dispostas em sequiência, sendo constatadas séries cristalíferas com até 16 cristais por série (figura 10). 

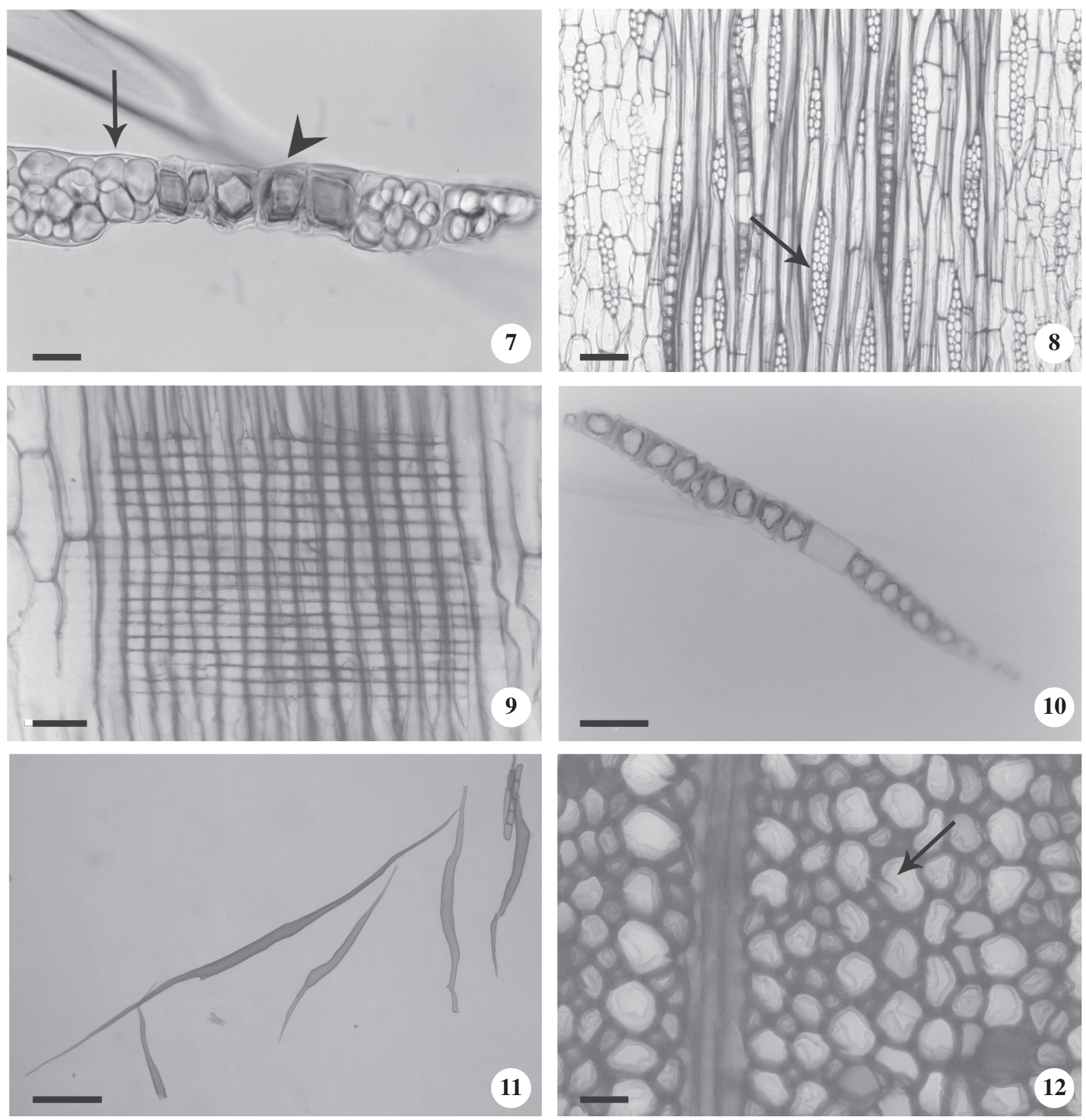

Figuras 7-12. Fotomicrografias do lenho do caule de Enterolobium contortisiliquum. 7, 10, 11. Lenho macerado. 8. Secção longitudinal tangenciail. 9. Secção longitudinal radial. 12. Secção transversal. 7. Célula subdividida do parênquima axial com grãos de amido (seta) e cristais (cabeça da seta). 8. Raios uni e multisseriados com até três células de largura (seta). 9. Raio homogêneo. 10. Células parenquimáticas contendo cristais prismáticos - série cristalífera. 11. Fibras com comprimentos variados. 12. Fibras com camadas gelatinosas (seta). Barra $=26 \mu \mathrm{m}$ (7); $250 \mu \mathrm{m}(8) ; 48 \mu \mathrm{m}$ (9); $24 \mu \mathrm{m}(10,12) ; 240 \mu \mathrm{m}(11)$.

Figures 7-12. Ligth micrographs of wood of stem of Enterolobium contortisiliquum. 7, 10, 11. Macerated wood. 8. Tangential longitudinal section. 9. Radial longitudinal section. 12. Transverse section. 7. Subdivided parenchyma cells with starch grains (arrow) and crystals (arrowhead). 8. Uni- and multisseriate rays up to three cells in width (arrow). 9. Homogeneous rays. 10. Prismatic crystals in chambered parenchyma cells - crystals in chains. 11. Fibres with varied lengths. 12. Fibres with gelatinous layers (arrow). Bar $=26 \mu \mathrm{m}$ (7); $250 \mu \mathrm{m}$ (8); $48 \mu \mathrm{m}$ (9); $24 \mu \mathrm{m}(10,12) ; 240 \mu \mathrm{m}(11)$. 
A presença de cristais em representantes da família Leguminosae também foi observada em indivíduos de Pseudopiptadenia contorta (Ribeiro \& Barros 2006), assim como em indivíduos de Copaifera langsdorffii presentes em floresta e cerradão (Marcati et al. 2001). Embora tenha sido evidente em todos os indivíduos examinados, houve predominância de cristais nos indivíduos dos ambientes mais secos, ou seja, ocorrentes em Buíque e Campina Grande. Fahn et al. (1986), estudando a flora de Israel e regiões adjacentes, encontraram maior número de espécies com cristais nas áreas com menor disponibilidade hídrica como nas regiões do Mediterrâneo e do deserto. Barajas-Morales (1985), comparando espécies de duas florestas (seca e úmida) do México, verificou presença de cristais apenas nas espécies da floresta seca. $\mathrm{O}$ aumento na frequiência de cristais em plantas em relação à diminuição da latitude foi observado por Baas (1973) para o gênero Ilex (Aquifoliaceaea), o que também foi verificado por Wilkins \& Papassotiriou (1989) para a espécies Acacia melanoxylon R. Br. A maior ocorrência de cristais nos indivíduos das áreas mais secas corrobora o observado por outros autores. A verdadeira função dos cristais em plantas é, até hoje, pouco conhecida, embora Franceschi \& Horner (1980) e Nakata (2003) tenham mencionado que eles podem constituir defesa contra a herbivoria e atuar na osmorregulação.

As fibras de E. contortisiliquum são libriformes, não septadas, e curtas, com comprimento médio de $1.097 \mu \mathrm{m}$ (figura 11). As suas paredes são muito finas, com aproximadamente $4 \mu \mathrm{m}$. Estas características estão de acordo com as citadas para o gênero (Metcalfe \& Chalk 1950) e para a espécie (Muñiz 1993). Observou-se a presença de fibras gelatinosas nos indivíduos de $E$. contortisiliquum (Figura 12). Segundo Paviani (1978), as fibras gelatinosas constituem-se em estruturas armazenadoras de água. Marcati et al. (2001) e Luchi (2004) citam maior quantidade de fibras gelatinosas no lenho de indivíduos ocorrentes em ambientes mais secos. Como os indivíduos de E. contortisiliquum ocorrentes nos quatro ambientes estudados passam por períodos de baixa disponibilidade hídrica é possível afirmar o importante papel das fibras gelatinosas não retenção de água no corpo da planta.

Os principais caracteres anatômicos do lenho de $E$. contortisiliquum, tais como a presença de camadas de crescimento, elementos de vaso muito curtos, placas de perfuração simples, pontoações guarnecidas, parênquima paratraqueal e fibras libriformes curtas estão entre os caracteres anatômicos mais importantes da família Leguminosae, citados na literatura.

A análise estatística descritiva dos valores tomados dos tipos celulares do lenho dos 20 indivíduos de $E$. contortisiliquum é apresentada na tabela 3 . A análise estatística descritiva dos valores médios dos elementos celulares dos indivíduos de cada ambiente (Buíque, Campina Grande, Taquara e Santa Maria) consta da tabela 4. A análise estatística descritiva revelou pequena diferença numérica entre as médias dos diâmetros tangenciais dos vasos das plantas dos quatro ambientes, sendo que a menor média foi a das plantas de Buíque. A análise de variância (ANOVA) detectou diferença estatisticamente significativa, em nível de $5 \%$ de probabilidade, entre as populações dos quatro locais (tabela 4). A diferença significativa entre as médias dos diâmetros tangencias dos vasos dos indivíduos dos dois ambientes do Nordeste (Buíque e Campina Grande) encontra suporte no fato de o primeiro ser um ambiente com menor disponibilidade hídrica (tabela 1). Esses

Tabela 3. Resultados da análise estatística descritiva de características anatômicas do lenho de Enterolobium contortisiliquum $(n=20)$.

Table 3. Results of descriptive statistical analysis of wood anatomy characteristics of Enterolobium contortisiliquum $(n=20)$.

\begin{tabular}{lrrrrrrr}
\hline Caráter anatômico & Média & Mediana & $\begin{array}{c}\text { Desvio } \\
\text { Padrão }\end{array}$ & $\begin{array}{c}\text { Coeficiente } \\
\text { de Variação }\end{array}$ & $\begin{array}{c}\text { Valor } \\
\text { Mínimo }\end{array}$ & $\begin{array}{c}\text { Valor } \\
\text { Máximo }\end{array}$ & Amplitude \\
\hline Diâmetro do vaso $(\mu \mathrm{m})$ & 197 & 197 & 47 & 24 & 17 & 342 & 325 \\
Comprimento do vaso $(\mu \mathrm{m})$ & 342 & 340 & 86 & 25 & 89 & 577 & 488 \\
Freqüência de vaso $\left(\mathrm{n}^{-} \mathrm{mm}^{-2}\right)$ & 2 & 2 & 1 & 68 & 1 & 15 & 5 \\
Comprimento da fibra $(\mu \mathrm{m})$ & 1098 & 1110 & 190 & 17 & 503 & 1628 & 1125 \\
Altura do raio $(\mu \mathrm{m})$ & 234 & 232 & 62 & 26 & 81 & 487 & 406 \\
Altura do raio $\left(\mathrm{n}^{\mathrm{o}}\right.$ de células) & 14 & 14 & 4 & 29 & 2 & 33 & 31 \\
Largura do raio $(\mu \mathrm{m})$ & 31 & 29 & 9 & 29 & 6 & 58 & 52 \\
Largura do raio $\left(\mathrm{n}^{-}\right.$de células) & 3 & 3 & 1 & 33 & 1 & 6 & 5 \\
\hline
\end{tabular}


resultados estão de acordo com o que sustentam vários autores, segundo os quais, os vasos das plantas em ambientes mais secos têm diâmetro menor (Outer \& Veenendaal 1976, Baas \& Carlquist 1985, Lindorf 1994). Eles são respaldados também pelos resultados obtidos por Luchi (2004) que examinou Croton urucurana Baill. em três áreas de mata (seca, úmida e alagada). Barajas-
Morales (1985), estudando espécies arbóreas ocorrentes em floresta tropical úmida e floresta tropical decidual no México, verificou menor diâmetro dos vasos nas espécies da floresta decidual, portanto, no ambiente mais seco, referendando os resultados obtidos em E. contortisiliquum. $\mathrm{O}$ menor diâmetro tangencial dos vasos em ambientes mais secos encontra suporte na afirmação de Levitt (1980).

Tabela 4. Resultados da análise estatística descritiva e da analise de variância (ANOVA) das características anatômicas do lenho de Enterolobium contortisiliquum $(n=5)$.

Table 4. Results of descriptive statistical analysis and analysis of variance wood anatomy characteristics of Enterolobium contortisiliquum $(n=5)$.

\begin{tabular}{|c|c|c|c|c|c|c|}
\hline \multirow{2}{*}{ Caráter anatômico } & \multirow{2}{*}{ Ambiente } & \multirow{2}{*}{$\begin{array}{c}\text { Média e } \\
\text { desvio padrão }\end{array}$} & \multirow{2}{*}{$\begin{array}{l}\text { Valor } \\
\text { mínimo }\end{array}$} & \multirow{2}{*}{$\begin{array}{l}\text { Valor } \\
\text { máximo }\end{array}$} & \multicolumn{2}{|c|}{ ANOVA } \\
\hline & & & & & $F$ & $P$ \\
\hline \multirow[t]{4}{*}{ Diâmetro do vaso $(\mu \mathrm{m})$} & Buíque & $179,0 \pm 44,0^{b}$ & 70 & 278 & 20,37 & 0,0001 \\
\hline & Campina Grande & $200,0 \pm 57,0^{\mathrm{a}}$ & 93 & 319 & & \\
\hline & Taquara & $196,0 \pm 38,0^{a}$ & 75 & 302 & & \\
\hline & Santa Maria & $211,0 \pm 41,0^{\mathrm{a}}$ & 17 & 342 & & \\
\hline \multirow[t]{4}{*}{ Comprimento do vaso $(\mu \mathrm{m})$} & Buíque & $356,0 \pm 99,0^{\mathrm{a}}$ & 104 & 577 & 7,03 & 0,0001 \\
\hline & Campina Grande & $345,0 \pm 85,0^{b}$ & 89 & 548 & & \\
\hline & Taquara & $326,0 \pm 81,0^{b}$ & 133 & 577 & & \\
\hline & Santa Maria & $342,0 \pm 73,0^{\mathrm{ab}}$ & 163 & 503 & & \\
\hline \multirow[t]{4}{*}{ Freqüência de vaso $\left(\mathrm{n}^{\mathrm{o}} \mathrm{mm}^{-2}\right)$} & Buíque & $2,0 \pm 1,0^{\mathrm{a}}$ & 1 & 6 & 6,44 & 0,0009 \\
\hline & Campina Grande & $1,6 \pm 1,1^{\mathrm{b}}$ & 1 & 8 & & \\
\hline & Taquara & $1,9 \pm 1,4^{\mathrm{ab}}$ & 1 & 15 & & \\
\hline & Santa Maria & $2,2 \pm 1,5^{\mathrm{a}}$ & 1 & 10 & & \\
\hline \multirow[t]{4}{*}{ Comprimento da fibra $(\mu \mathrm{m})$} & Buíque & $1155,0 \pm 186,0^{\mathrm{a}}$ & 503 & 1628 & 77,05 & 0,0001 \\
\hline & Campina Grande & $1175,0 \pm 161,0^{a}$ & 770 & 1584 & & \\
\hline & Taquara & $966,0 \pm 177,0^{c}$ & 577 & 1480 & & \\
\hline & Santa Maria & $1098,0 \pm 164,0^{b}$ & 533 & 1628 & & \\
\hline \multirow[t]{4}{*}{ Altura do raio $(\mu \mathrm{m})$} & Buíque & $233,0 \pm 61,0^{\mathrm{ab}}$ & 110 & 452 & 8,90 & 0,0001 \\
\hline & Campina Grande & $239,0 \pm 64,0^{\mathrm{a}}$ & 81 & 487 & & \\
\hline & Taquara & $244,0 \pm 66,0^{a}$ & 93 & 470 & & \\
\hline & Santa Maria & $219,0 \pm 53,0^{b}$ & 87 & 406 & & \\
\hline \multirow[t]{4}{*}{ Altura do raio (no de células) } & Buíque & $13,0 \pm 3,0^{\mathrm{bc}}$ & 5 & 26 & 11,93 & 0,0001 \\
\hline & Campina Grande & $14,0 \pm 4,0^{\mathrm{ab}}$ & 5 & 31 & & \\
\hline & Taquara & $15,0 \pm 4,0^{\mathrm{a}}$ & 7 & 33 & & \\
\hline & Santa Maria & $13,0 \pm 4,0^{c}$ & 2 & 25 & & \\
\hline \multirow[t]{4}{*}{ Largura do raio $(\mu \mathrm{m})$} & Buíque & $33,0 \pm 9,0^{\mathrm{a}}$ & 6 & 58 & 2,67 & 0,0570 \\
\hline & Campina Grande & $28,0 \pm 7,0^{\mathrm{a}}$ & 12 & 46 & & \\
\hline & Taquara & $32,0 \pm 9,0^{\mathrm{a}}$ & 17 & 58 & & \\
\hline & Santa Maria & $30,0 \pm 7,0^{\mathrm{a}}$ & 6 & 52 & & \\
\hline \multirow[t]{4}{*}{ Largura do raio (nº de células) } & Buíque & $3,3 \pm 1,1^{\mathrm{a}}$ & 1 & 6 & 25,24 & 0,0001 \\
\hline & Campina Grande & $2,3 \pm 0,6^{c}$ & 1 & 4 & & \\
\hline & Taquara & $3,1 \pm 0,8^{\mathrm{a}}$ & 2 & 5 & & \\
\hline & Santa Maria & $2,8 \pm 0,7^{\mathrm{b}}$ & 1 & 5 & & \\
\hline
\end{tabular}

Valores seguidos das mesmas letras não diferiram significativamente entre si pelo teste de Tukey, $\alpha=0,05$. Values followed by the same letter did not differ significantly according to Tukey-tests, $\alpha=0,05$. 
Segundo o autor, a distensão da célula vegetal depende do turgor celular. Conseqüentemente, a manutenção da disponibilidade hídrica permite que as células cambiais em diferenciação cresçam mais rapidamente. As plantas ocorrentes em Buíque, em virtude da baixa precipitação e médias de temperatura mais alta entre as quatro áreas, devem ter sofrido esse efeito.

Para a média do comprimento dos vasos a análise estatística descritiva evidenciou menores valores médios nos indivíduos de Taquara e maiores nos indivíduos de Buíque. A ANOVA detectou diferença estatisticamente significativa entre os dois indivíduos do Nordeste. As médias de comprimento de vasos dos indivíduos ocorrentes em Campina Grande, Taquara e Santa Maria não diferiram entre si e as populações de Buíque e de Santa Maria, apesar da grande diferença nas condições climáticas, também não revelaram diferença significativa (tabela 4). Foi observada uma tendência de vasos mais compridos nas populações do Nordeste em comparação com as populações da região Sul. Esta situação está de acordo com o observado em Acacia melanoxylon (Wilkins \& Papassotiriou 1989) e Dodonaea viscosa Jacq. (Liu \& Noshiro 2003), que encontraram vasos mais compridos em indivíduos ocorrentes em menores latitudes. Em trabalhos que compararam ambientes xéricos e mésicos foi registrada uma tendência de vasos mais curtos nos locais mais secos, como comprovaram em outros estudos (Carlquist 1966, Baas \& Carlquist 1985, Carlquist \& Hoekman 1985, Barajas-Morales 1985, Lindorf 1994). Neste trabalho não foi comprovada esta tendência, visto que foram observados elementos de vasos mais compridos em indivíduos ocorrentes em Buique (PE) e Campina Grande (PB), justamente os dois ambientes mais secos. Acredita-se que a diferença entre os resultados encontrados neste trabalho e os citados acima, possa estar no fato de que os autores citados realizaram estudos de floras de determinadas regiões, portanto, com abordagem de um grande número de espécies. Nesse tipo de análise, trabalha-se com a tendência geral observada para o conjunto dos indivíduos da flora e não de cada espécie isoladamente com ocorreu neste estudo.

As médias de frequiência de vasos encontradas nos indivíduos de cada ambiente ficaram em 2 vasos por $\mathrm{mm}^{2}$, embora os valores de máximo e mínimo tenham variado bastante, especialmente no indivíduos de Taquara, onde se observou valores máximos de até 15 vasos por $\mathrm{mm}^{2}$. A ANOVA detectou diferença significativa entre as populações dos dois ambientes da região Nordeste (tabela 4). De acordo com o teste de comparação múltipla de médias (Tukey a 5\%), as freqüências dos vasos não foram estatisticamente significativas entre os dois locais da região
Sul (Taquara e Santa Maria). Entretanto, as médias de freqüêência de vasos por $\mathrm{mm}^{2}$ em Santa Maria e em Buíque foram significativamente diferentes de Campina Grande. Esta diferença significativa quanto à freqüência de vasos entre os dois ambientes da região Nordeste foi detectada, também, na análise das outras duas variáveis referentes aos vasos, diâmetro tangencial dos vasos e comprimento dos elementos de vaso. Marcati et al. (2001) também não observaram variação na frequiência de vasos em indivíduos de Copaifera langsdorffii ocorrentes em floresta e cerradão. Os resultados encontrados para $E$. contortisiliquum não coincidem com as observações feitas por outros autores, a exemplo de Baas (1973), ao estudar espécies do gênero Ilex, Noshiro \& Baas (2000), ao analisarem indivíduos de Cornus macrophylla Wall., e Wilkins \& Papassotiriou (1989), ao estudarem Acacia melanoxylon, ocorrentes em ambientes distintos e verificarem maior frequiência de vasos nos ambientes mais secos. A baixa frequiência de vasos por $\mathrm{mm}^{2} \mathrm{em} E$. contortisiliquum, independente do local, parece ser compensada por outras estratégias, como por exemplo o caráter decíduo da espécie.

Coincidindo com as diferenças ambientais, as médias dos comprimentos das fibras foram mais altas nas plantas dos dois ambientes da região Nordeste. Por meio da ANOVA, foi detectada diferença significativa entre as populações dos diferentes ambientes e o teste de comparação múltipla de médias (tabela 4), separando-se os ambientes em três grupos: o primeiro, formado pelas plantas da região Nordeste (Buíque e Campina Grande), o segundo, pelos indivíduos de Santa Maria, e, o terceiro, pelos de Taquara. A comparação das médias de comprimento de fibras apresentou um resultado coerente com as características dos ambientes. De um modo geral, comprimento médio das fibras é uma característica de difícil relação com latitude e ambiente mésico ou xérico, devido à variação ao longo do corpo da planta nos sentidos radial e axial, além da idade do indivíduo, característica de difícil diagnóstico em plantas de ambientes naturais. A associação do comprimento das fibras com o ambiente foi observada nos trabalhos de Baas 1973, Graaff \& Baas 1974, Oever et al. 1981, Noshiro \& Baas 2000). Nesses trabalhos, fibras mais curtas foram registradas em plantas que vegetavam em ambientes mais secos, como foi observado por Barajas-Morales (1985), que encontrou fibras mais longas em espécies de uma floresta úmida em comparação com as espécies ocorrentes em floresta seca. Resultados semelhantes foram obtidos por Carlquist (1966), que, ao comparar a estrutura do lenho de 328 espécies da família Compositae, observou menor comprimento das fibras nos locais com menor precipitação 
média anual. Os resultados obtidos em E. contortisiliquum divergiram claramente dos apresentados pelos autores citados, visto que fibras mais longas foram observadas nos indivíduos de ambientes mais secos. Porém, dados semelhantes aos deste trabalho foram encontrados por Marcati et al. (2001), ao compararem indivíduos de Capaifera langsdorffi, ocorrentes em floresta e cerradão, e observarem valores médios de comprimento de fibras de $973 \mu \mathrm{m}$ para o cerradão e de $963 \mu \mathrm{m}$ para os indivíduos da floresta. Embora haja registros da presença de fibras mais curtas em plantas vegetando em ambientes mais secos esta tendência não se confirmou nas amostras de E. contortisiliquum.

A altura e a largura dos raios são expressas de duas formas na literatura. Alguns trabalhos as apresentam em micrômetros (Graaff \& Baas 1974, Outer \& Veenendaal 1976, Oever et al. 1981), outros, em número de células (Carlquist 1966, Oever et al. 1981, Wilkins \& Papassotiriou 1989, Alves \& Angyalossy-Alfonso 2000, Luchi 2004). Isso dificulta a comparação entre os resultados dos diferentes autores. Assim, neste trabalho, estas variáveis foram mensuradas nas duas unidades, visando uma melhor comparação com dados da literatura. A análise estatística descritiva encontrou valores médios das alturas dos raios, em micrômetros e em número de células, muito próximos entre os indivíduos dos ambientes do Nordeste, Buíque (233 um e 13 células) e Campina Grande ( $239 \mu$ m e 14 células). Na região Sul, as plantas de Taquara apresentaram os maiores valores médios de altura dos raios ( $244 \mu \mathrm{m}$ e 15 células), em relação àqueles de Santa Maria ( $219 \mu \mathrm{m}$ e 13 células). AANOVA detectou diferença significativa entre os ambientes e o teste de Tukey (Tabela 4) indicou que houve diferença significativa entre as populações da região Sul (Taquara e Santa Maria). Diferentemente da análise dos valores de diâmetro tangencial dos vasos, comprimento dos elementos de vaso e frequência dos vasos, em que as duas populações da região Nordeste diferiram entre si, neste caso não foi detectada diferença significativa.

AANOVA detectou diferença significativa entre as populações vegetando em área de Floresta em Santa Maria e de Campina Grande, um ambiente de caatinga, indicando uma tendência entre altura dos raios e disponibilidade hídrica. O que foi comprovado por alguns registros indicando raios mais altos em plantas de ambientes mais xéricos, como mostraram (Baas 1973, Graaff \& Baas 1974, Outer \& Veenendaal 1976, Oever et al. 1981). Porém, Barajas-Morales (1985), estudando plantas de duas florestas tropicais mexicanas (seca e úmida), verificou a presença de raios mais altos nas plantas ocorrentes na floresta úmida.
Com relação a largura dos raios a análise estatística descritiva revelou que as médias em micrômetro e em número de células pouco variaram, ficando entre $28 \mathrm{e}$ $33 \mu \mathrm{m}$ e 2 e 3 células. As médias registradas para as plantas das plantas das regiões Sul e Nordeste foram muito próximas. Com relação a largura dos raios em micrômetro a ANOVA (Tukey 5\%) não revelou diferença significativa entre as quatro populações. Para a largura dos raios em numero de células o teste de Tukey (Tabela 4) separou as médias das populações em três grupos: o primeiro, constituído por Buíque e Taquara; o segundo, por Santa Maria; e o último, por Campina Grande. As informações sobre a largura dos raios na literatura são contraditórias. Carlquist (1966), estudando espécies da família Asteraceae, encontrou raios mais largos em indivíduos de ambientes mais secos. Alves \& AngyalossyAlfonso (2002), estudando as tendências ecológicas do lenho de espécies brasileiras ocorrentes nas cinco regiões geográficas, e em vários tipos de clima e vegetação, encontraram maior frequiência de raios unisseriados no semi-árido nordestino e na vegetação de caatinga. No presente trabalho, não foi observada essa tendência no lenho de E. contortisiliquum, que apresentou raios mais largos nos indivíduos de Buíque, justamente o local mais seco, e que fica no semi-árido e na vegetação de caatinga. Resultado semelhante foi encontrado por Luchi (2004), estudando Croton urucurana (Euphorbiaceae), em solo com diferentes níveis de umidade. A autora encontrou raios mais largos nos indivíduos da área seca em comparação àqueles das áreas úmida e alagada. A discordância entre os resultados confirma a falta de relação, entre a altura e/ou a largura dos raios com caráter xérico ou mésico do ambiente. Essa interpretação também pode decorrer da falta de dados na literatura visto que poucos autores abordaram essas características do lenho em seus estudos de anatomia ecológica.

Cabe destacar que as tendências ecológicas de constituintes do lenho devem ser vistas em combinação com outros aspectos da biologia da planta, pois a evolução não trabalha em uma ou poucas frentes para produzir o ajuste de um grupo vegetal a uma situação de estresse, mas em diversas direções. Assim, quando a anatomia do lenho parece não estar de acordo com o grau de xeromorfia esperado, deve-se procurar explicações de outros tipos de adaptações.

Uma arquitetura hidráulica segura, porém, suficientemente eficiente, é somente uma das síndromes integradas com diferentes adaptações na estrutura da folha, fenologia, sistema radicular e padrões metabólicos e fotossintéticos. Da mesma forma, segurança e eficiência do lenho podem ser conseguidas de maneiras diferentes. 
Muitas plantas, especialmente aquelas de ambientes xéricos, reúnem grande frequiência de vasos de diâmetro pequeno, ou de diâmetros diferentes visando, principalmente, à segurança do fluxo hídrico. Em E. contortisiliquum, o que se observou foi a ocorrência de vasos com grande diâmetro tangencial e poucos vasos por $\mathrm{mm}^{2}$. Tudo indica que a planta parece investir mais na eficiência que na segurança, o que se explica por se tratar de uma espécie pioneira. Assim, é provável que a segurança seja garantida por outros órgãos ou por mecanismos fisiológicos da planta, como, por exemplo, a presença das camadas de crescimento, uma vez que estas surgem nos períodos de estresse para a planta, levando a uma diminuição na atividade cambial e, conseqüentemente, a uma redução nas dimensões das células que compõem o lenho, entre as quais, os vasos. Assim, no período em que aumenta o risco de embolias, a planta desenvolve vasos menores e, conseqüentemente, mais seguros. Outra estratégia apresentada pelos indivíduos de E. contortisiliquum, comprovadamente relacionada com a segurança, foi a ocorrência de pontoações guarnecidas, visto que estas podem auxiliar na diminuição do risco de embolias. A maior presença de fibras gelatinosas no lenho dos indivíduos de Buíque e Campina Grande, áreas mais secas em comparação com Taquara e Santa Maria, indica que elas podem auxiliar na retenção de água no corpo da planta, configurando outra estratégia de sobrevivência em ambientes secos. A maior freqüência de cristais de oxalato de cálcio nos indivíduos de Buíque e Campina Grande está de acordo com a literatura, que indica ocorrência maior de cristais em plantas de ambientes mais secos. É importante lembrar que a composição química do solo deve influenciar a ocorrência de cristais em plantas, e, portanto, estudos neste sentido devem ser aprofundados.

Apesar da existência de tendências gerais, relacionando a estrutura do lenho com o ambiente, expressa em um número representativo de espécies, há ainda uma proporção de espécies, também representativa, que não segue tais tendências, como registrado em E. contortisiliquum.

Agradecimentos - Os autores agradecem ao Dr. Jorge Ernesto de Araújo Mariath (Instituto de Biociências, Departamento de Botânica, UFRGS), por disponibilizar a estrutura do Laboratório de Anatomia Vegetal; às $\operatorname{Dr}^{\text {as }}$ Ana Luiza du Bocage e Rita de Cássia Araújo Pereira (Herbário IPA Dárdano de Andrade-Lima da Empresa Pernambucana de Pesquisas Agropecuárias - IPA), pela identificação do material botânico; à Dra. Maria Alice Neves (Departamento de Sistemática e Ecologia, UFPB), pela leitura crítica e sugestões ao manuscrito; ao Centro de Microscopia Eletrônica da Universidade Federal do Rio Grande do Sul -
CME, pelo uso das instalações e à Coordenação de Aperfeiçoamento de Pessoal de Nível Superior (Capes), pela concessão da bolsa de doutorado para o primeiro autor.

\section{Referências bibliográficas}

ALVES, E.S. \& ANGYALOSSY-ALFONSO, V. 2000. Ecological trends in the wood anatomy of some Brazilian species. 1. Growth rings and vessels. IAWA Journal 21:3-30.

ALVES, E.S. \& ANGYALOSSY-ALFONSO, V. 2002. Ecological trends in the wood anatomy of some Brazilian species. 2. Axial parenchyma, rays and fibers. IAWA Journal 23:391-418.

ANGYALOSSY-ALFONSO, V. \& MILLER R.B. 2002. Wood anatomy of the Brazilian species of Swartzia and considerations within the tribe Swartzieae. IAWA Journal 23:359-390.

BAAS, P. 1973. The wood anatomical range in Ilex (Aquifoliaceae) and its ecological and phylogenetic significance. Blumea 21:193-258.

BAAS, P. \& S. CARLQUIST. 1985. A comparation of the ecological wood anatomy of the floras of southern California and Israel. IAWA Bulletin 6:349-353.

BAILEY, I.W. 1933. The cambium and its derivate tissues VIII. Structure, distribution and diagnostic significance of the vestured pits in dicotyledons. Journal Arnold Arbor 14:259-273.

BARAJAS-MORALES, J. 1985. Wood structural differences between trees of two tropical forests in Mexico. IAWA Bulletin 6:355-364.

BRAUN, H.J. 1984. The significance of the acessory tissues of the hydrosystem for osmotic water shifting as the second principle of water ascent, with some thoughts concerning the evolution trees. IAWA Bulletin 5:275294.

CARLQUIST, S. 1966. Wood anatomy of Compositae: a summary, with comments on factors controlling wood evolution. Aliso 6:25-44.

CARLQUIST, S. 2001. Comparative wood anatomy: systematic, ecological and evolutionary aspects of dicotyledons wood. Springer Verlag, Berlin.

CARLQUIST, S. \& D.A. HOEKMAN. 1985. Ecological wood anatomy of woody southern California flora. IAWA Bulletin 6:319-347.

FAHN, A., E. WERKER \& P. BAAS. 1986. Wood anatomy and identification of trees and shrubs from Israel and adjacent regions. The Israel Academy of Sciences and Humanities, Jerusalem.

FEDALTO, L.C., MENDES, I.C.A. \& CORADIN, V.T.R. 1989. Madeiras da Amazônia: Descrição do lenho de 40 espécies ocorrentes na floresta nacional do Tapajós. IBAMA, Brasília.

FRANCESCHI, V.R. \& HORNER, H.T. 1980. Calcium oxalate crystals in plant. The Botanical Review 46:361-427. 
GOULART, S.L. \& MARCATI, C.R. 2008. Anatomia comparada do lenho em raiz e caule de Lippia salviifolia Cham. (Verbenaceae). Revista Brasileira de Botânica 31:263-275.

GRAAFF, N.A. VAN DER. \& P. BAAS. 1974. Wood anatomical variation in relation to latitude and altitude. Blumea 22:101-121.

HACKE, U.G. \& SPERRY, J.S. 2003. Limits to xylem refilling under negative pressure in Laurus nobilis and Acer negundo. Plant Cell and Environment 26:303-311.

IAWA COMMITTEE. 1964. Multilingual glossary of terms used in wood anatomy. Konkordia, Winterthur.

IAWA COMMITTEE. 1989. IAWA list of microscopic features for hardwood identification. IAWA Bulletin 10:219-332.

IQBAL, M. \& GHOUSE, A.K.M. 1987. Anatomy of the vascular cambium of Acacia nilotica (L.) Del. var. telia Troup (Mimosaceae) in relation to age and season. Botanical Journal of the Linnean Society 94:385-397.

JANSEN, S., BAAS, P. \& SMETS, E. 2001. Vestures pits: their occurrence and systematic importance in eudicots. Taxon 50:135-167.

JANSEN, S., BAAS, P., GASSON, P., LENS, F. \& SMETS, E. 2004. Variation in xylem structure from tropics to tundra: evidence from vestured pits. Proceedings of the National Academy of Sciences of the USA 101: 8833-8837.

JANSEN, S., SMETS, E. \& BAAS, P. 1998. Vestures in woody plants: A review. IAWA Journal 19:347-382.

JOHANSEN, D.A. 1940. Plant microtechnique. McGraw Hill, London.

KRAUS, J.E. \& ARDUIN, M. 1997. Manual básico de métodos em morfologia vegetal. EDUR. Seropédica, Rio de Janeiro.

LEVITT, J. 1980. Responses of plants to environmental stresses. v.I - Chilling, freezing and high temperature stresses. Physiological Ecology - a series of monographs, texts and treatises. Academic Press, New York.

LEWIS, G.P., SCHRIRE, B., MACKINDER, B. \& LOCK, M. 2005. Legumes of the word. Kew, Richmond, Royal Botanic Garden, Kew.

LINDORF, H. 1994. Eco-anatomical wood features of species from a very dry tropical forest. IAWA Journal 15:363-376.

LIU, J. \& NOSHIRO, S. 2003. Lack of latitudinal trends in wood anatomy of Dodonaea viscosa (Sapindaceae), a species with a worldwide distribution. American Journal of Botany. 90:532-539.

LOUREIRO, A.A. \& LISBOA, P.L.B. 1979. Anatomia do lenho de seis espécies de Ormosia (Leguminosae) da Amazônia. Acta Amazonica 9:731-746.

LUCHI, A.E. 2004. Anatomia do lenho de Croton urucurana Baill. (Euphorbiaceae) de solos com diferentes níveis de umidade. Revista Brasileira de Botânica 27:271-280.

MAINIERI, C. \& CHIMELO, J.P. 1989. Fichas de características das madeiras brasileiras. (publicação IPT 1791) Instituto de Pesquisas Tecnológicas, São Paulo.
MARCATI, C.R., ANGYALOSSY-ALFONSO, V. \& BENETATI, L. 2001. Anatomia comparada do lenho de Copaifera langsdorffii Desf. (LeguminosaeCaesalpinoideae) de floresta e cerradão. Revista Brasileira de Botânica 24:311-320.

MARCATI, C.R., OLIVEIRA, J.S. \& MACHADO, S.R. 2006. Growth rings in cerrado wood species: occurrence and anatomical markers. Biota Neotropica 6:1-31.

MAZZONI-VIVEIROS, S. C. 2000. Diversidade do uso da anatomia: poluição atmosférica na Mata Atalnântica. In: Tópicos atuais em Botânica (T.B. Cavalcante \& B.M.T. Walter, eds.). Sociedade Botânica do Brasil/ Embrapa-Cenargen. Brasília, p.101-106.

MESQUITA, A.L. 1990. Revisão taxonômica do gênero Enterolobium contortisiliquum (Mimosoideae), para a região neotropical. Dissertação de mestrado, Universidade Federal Rural de Pernambuco, Recife.

METCALFE, C.R. \& CHALK, L. 1950. Anatomy of the dicotyledons, v.I. Clarendon Press, Oxford.

MUÑIZ, G.I.B. 1993. Anatomia da madeira de espécies arbóreas da Floresta Estacional semidecidual de Misiones, Argentina. Tese para o concurso de professor titular, Universidade Federal do Paraná, Curitiba.

NAKATA, P.A. 2003. Advances in our understanding of calcium oxalate crystal formation and function in plant. Plant Science 164:901-909.

NOSHIRO, S. \& BAAS, P., 2000. Latitudinal trends in wood anatomy species and genera: case study in Cornus s.I. (Cornaceae). American Journal of Botany 87:1495-1506.

OEVER, L. van den., BAAS, P. \& ZANDEE, M. 1981. Comparative wood anatomy of Symplocos and latitude and altitude of provenance. IAWA Bulletin 2:3-24.

OHTANI, J. \& ISHIDA, S. 1976. Study on the pit of wood cells using scanning electron microscopy. 5. Vestured pits in Japanese dicotyledonous woods. Research Bulletins of the College Experiment Forest, College of Agriculture, Hokkaido University 33:407-435.

OUTER, R.W. den \& VEENENDAAL, W.L.H. 1976. Variation in wood anatomy of species with a distribution covering both rain forest and savanna areas of the Ivory Coast, West-Africa. Leiden In Wood structure in biological and technological research (P. Baas., A.J. Bolton \& D.M. Catling, eds.) Leiden Botanical Series, n.3, Leiden University Press, Leiden, p.182-195.

PAVIANI, T.I. 1978. Anatomia vegetal e cerrado. Ciência \& Cultura 30:1076-1086.

RIBEIRO, M.L.R.C. \& BARROS, C.F. 2006. Variação intraspecifica do lenho de Pseudopiptadenia contorta (DC.) G.P. Lewis \& M.P. Lima (Legumonosae Mimosoideae) de populações ocorrentes em remanescentes de Floresta Atlântica. Acta Botanica Brasilica 20:839-844.

SPERRY, J.S., HACKE, U.G., OREN, R. \& COMSTOCK, J.P. 2002. Water deficits and hydraulic limits to leaf water supply. Plant Cell and Environment 25:251-263. 
WATANABE, Y., SANO, Y., ASADA, T. \& FUNADA, R. 2006. Histochemical study of the chemical composition of vestured pits in two species of Eucalyptus. IAWA Journal 27:33-43.

WILKINS, A.P. \& PAPASSOTIRIOU, S. 1989. Wood anatomical variation of Acacia melanoxylon in relation to latitude. IAWA Bulletin 10:201-207.
WHEELER, E.A. \& BAAS, P. \& RODGERS, S. 2007. Variations in dicot wood anatomy: a global analysis based on the insidewood database. IAWA Journal 28:229-259.

ZWEYPFENNING, R.C.V.J. 1978. A hypothesis on the function of vestured pits. IAWA Bulletin 1:3-15. 